
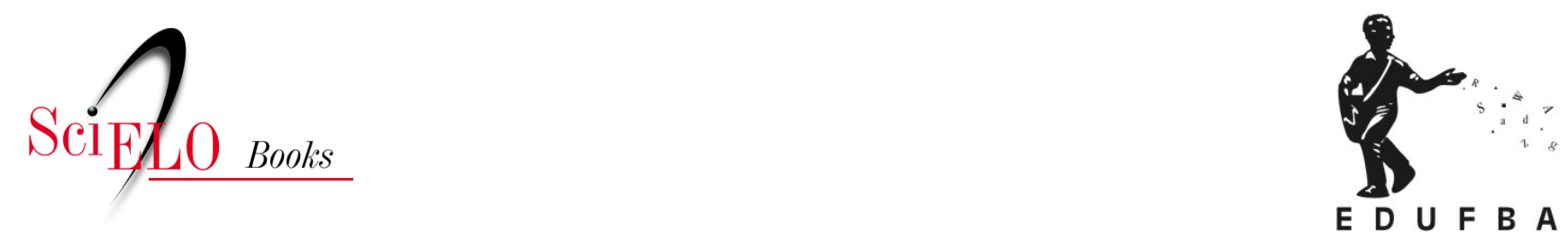

\title{
A inocência racial e o direito costumeiro de regulação racial
}

\author{
Tanya Katerí Hernández \\ Arivaldo Santos de Souza \\ Luciana Carvalho Fonseca \\ (Tradutores)
}

\section{SciELO Books / SciELO Livros / SciELO Libros}

HERNÁNDEZ, T.K. A inocência racial e o direito costumeiro de regulação racial. In: Subordinação racial no Brasil e na América Latina: o papel do Estado, o Direito Costumeiro e a Nova Resposta dos Direitos Civis [online]. Translated by Arivaldo Santos de Souza and Luciana Carvalho Fonseca. Salvador: EDUFBA, 2017, pp. 15-30. ISBN: 978-85-232-2015-0. https://doi.org/10.7476/9788523220150.0003. \section{International license.}

All the contents of this work, except where otherwise noted, is licensed under a Creative Commons Attribution 4.0

Todo o conteúdo deste trabalho, exceto quando houver ressalva, é publicado sob a licença Creative Commons Atribição $\underline{4.0}$. 


\section{A inocência racial e o direito costumeiro de regulação racial}

Não acho que exista muito racismo na América Latina porque somos uma mistura de raças de todos os tipos, europeus, africanos, asiáticos e outras raças que existiram e existirão; mas entendo que exista racismo em muitas outras partes, principalmente nos Estados Unidos e na Europa, lá é onde existe mais racismo. (IBEROAMÉRICA, 2005)

Há cerca de 150 milhões de pessoas de ascendência africana na América Latina, representando cerca de um terço da população total (ver mapas 1 e 2). (SÁNCHEZ; BRYAN, 2003, p. 3-4) Todavia, esses são dados que podem ser considerados conservadores se levarmos em conta o histórico de subcontagem dos afrodescendentes nos censos latino-americanos, os quais frequentemente não apresentam um campo para registrar a origem étnica/racial dos entrevistados. (HOOKER, 2008, p. 279-281) Ao mesmo tempo, os afrodescendentes representam mais de $40 \%$ da população latino-americana pobre e têm sido tradicionalmente marginalizados e inferiorizados por serem considerados elementos indesejáveis pela sociedade desde a abolição da escravidão nos diversos países americanos. (GATES JUNIOR, 2011; MÁRQUEZ et al., 
2007, p. 15-17) Ainda assim, a visão de que "racismo não existe" é bastante difundida na América Latina, a despeito do advento dos movimentos sociais negros e de cientistas sociais demonstrarem o contrário. Quando a BBC entrevistou latino-americanos, em 2005, sobre a existência de racismo na região, um número significativo de pessoas enfaticamente negou sua existência. Muitos, por exemplo, falaram que "ibero-americanos não são racistas" e que "A América Ibérica não é uma região racista pelo simples fato de ser a maioria da população indígena, crioula ou mestiça”. (IBEROAMÉRICA, 2005)

Assim, a negação do racismo está enraizada no que muitos acadêmicos chamam de o "mito da democracia racial" - a noção de que a mestiçagem (mestizaje, em castelhano) em uma população é uma característica emblemática de harmonia racial e impossibilita discórdia e desigualdade racial. As pesquisas acadêmicas nos últimos 20 anos têm criticado as teorias latino-americanas de "mestiçagem”, segundo as quais a mistura seria a marca registrada da harmonia racial. Contudo, os latino-americanos continuam defendendo a noção de que, ao contrário dos Estados Unidos, por haver na região uma grande miscigenação, inexiste respaldo jurídico no estilo da legislação ${ }^{1}$ Jim Crow, tornando a América Latina "racialmente inocente", termo cunhado por mim. De fato, uma ampla pesquisa, Americas Barometer 2010, do Projeto Opinião Pública na América Latina, demonstrou que as ideologias latino-americanas racialmente preconceituosas não evoluíram completamente a despeito da existência de críticas acadêmicas à ideia de mestiçagem como uma alegoria para a inocência racial. Por exemplo, na pesquisa Americas Barometer 2010 na Bolívia, Brasil, Colômbia, República Dominicana, Equador, Guatemala, México e Peru, a grande maioria das populações (de todas as raças), ao ser indagada sobre a noção de mestiçagem, considerava que "a mistura racial é boa para o país". (LATIN AMERICAN PUBLIC OPINION PROJECT OF VANDERBILT UNIVERSITY, 2010b) De fato, mais de $75 \%$ de todos os entrevistados concordaram com a ideia de mestiçagem e expressaram ampla aprovação à prática de casamentos inter-raciais. Contudo, os dados do Americas Barometer também mostraram que o número de latino-americanos que desaprovaram a ideia de seus filhos casarem com parceiros negros foi exponencialmente superior entre os brancos em relação aos

1 Conjunto de normas aprovadas ou intencionalmente interpretadas com o fim de discriminar negros, como as leis que determinavam banheiros separados para brancos e negros. (GARNER, 2005, p. 694) (N.T.) 
negros. Mais especificamente, nos países onde o Americas Barometer perguntou se os entrevistados aprovariam uma união entre um filho e uma pessoa negra, no caso do Brasil, Colômbia, República Dominicana e Equador, a reprovação por parte dos brancos foi, em média, $60 \%$ maior do que a reprovação por parte dos negros (em outros países, os entrevistados foram perguntados sobre casamento com pessoas de ascendência indígena). Assim, tais resultados estão de acordo com as tradicionais estatísticas que apontam os casamentos latino-americanos como, de maneira geral, racialmente endogâmicos. (WADE, 2009, p. 168-173)

Os dados da pesquisa Americas Barometer 2010 também indicam que os entrevistados brancos em vários países latino-americanos são consideravelmente mais propensos que os entrevistados de outros grupos a declararem preferência por pessoas de pele mais clara. Por exemplo, na Colômbia, no Equador e na República Dominicana, em média, 26\% dos entrevistados brancos afirmaram que preferiam pessoas de pele clara. Em contrapartida, em média, 13\% dos entrevistados negros afirmaram preferir pessoas de pele clara. No México e no Peru, negros, em média, tinham maiores taxas de preferência por pessoas de pele clara (37\%) do que brancos (26\%). No Brasil, a taxa de preferência por pessoas de pele mais clara foi bem parecida em ambos os grupos. Mesmo a Cuba socialista segue preferindo a branquitude e a população branca segue rejeitando casamentos inter-raciais. Além do mais, em uma comparação (de 2004) do preconceito racial implícito e explícito nos Estados Unidos, Cuba, República Dominicana e Porto Rico, as taxas de preconceito racial explícito e implícito foram mais altas nos três países latino-americanos em comparação às taxas americanas. (PEÑA; SIDANIUS; SAWYER, 2004, p. 749-762) Desse modo, a despeito da esmagadora articulação da mestiçagem como um indicador de harmonia racial na maior parte da América Latina e os diferentes modos que a articulação se dá em cada país, as atitudes de discriminação racial subjazem à aclamada miscigenação. Em parte, a ausência de uma crítica jurídica envolvendo uma comparação entre as leis norte-americanas Jim Crow e os sistemas jurídicos latino-americanos têm permitido que o discurso de "inocência racial" latino-americana persista. Este livro busca preencher essa lacuna na literatura acadêmica sobre o tema e fornecer uma crítica jurídica.

Especificamente, este livro trata das formas como a negação latino-americana do racismo é operada juntamente com a noção de que o verdadeiro racismo só pode ser encontrado na segregação racial estadunidense, fazendo com que as 
manifestações de racismo na América Latina permaneçam veladas. Meu argumento é que um exame do papel do Estado no período subsequente à abolição da escravidão na regulação das relações raciais por meio de leis de imigração e do direito costumeiro rompe com a imagem de que a América Latina é uma região "racialmente inocente". Em seguida, avalio as formas pelas quais, atualmente, as legislações latino-americanas referentes à igualdade racial estão tentando erradicar o legado de desigualdade racial forjado pelo racismo estatal perpetuado ao longo da história. Por fim, concluirei o livro com insights sobre como o exame do contexto latino-americano pode ser de valia aos movimentos negros estadunidenses de hoje. Ao realizar este trabalho, emprego o termo "afrodescendentes" que acadêmicos e ativistas usam para designar todas as pessoas latino-americanas de ascendência africana que são afetadas pelo sentimento antinegro, quer elas se autoidentifiquem (ou não) como negras, quer adotem uma identidade multirracial, como a de mulato ou mestiço. Este livro não abordará assuntos de desigualdade racial em relação a grupos indígenas latino-americanos, uma vez que já existe uma vasta literatura sobre o assunto. A análise deste livro será focada na história das relações dos afrodescendentes com o Estado, enquanto ex-escravizados reivindicando cidadania e participação integral na identidade nacional a despeito da negação social da existência de racismo.

\section{“Não somos racistas!”. A negação do racismo como máscara da discriminação racial}

A força da negação do racismo na América Latina é tão grande que mesmo sua expressão generalizada e a disseminação do discurso racista são vistos como algo irrelevante. Contudo, o termo "negro" é amplamente considerado depreciativo, uma vez que pessoas de ascendência africana são estereotipadas e consideradas essencialmente criminosas, intelectualmente inferiores, excessivamente sexuais e animalescas. Por serem muito comuns na região, os estereótipos raciais ligados às pessoas de ascendência africana, entende-se que as mesmas cheiram a animais, em particular, a macacos. Além dos estereótipos comuns acerca dos negros na América Latina, cada país da região também desenvolveu seu próprio subconjunto de termos depreciativos para se referir aos negros e à negritude.

Na Argentina, "negro de mierda" ("negro de merda") é uma expressão popular (COURTIS et al., 2009, p. 13, 32), e "negro" é visto como o pior dos insultos. (ARI, 
2010) Como resultado, mesmo as canções infantis argentinas são repletas de referências antinegros, tais como "Eu gosto do branco, vida longa para o branco, morte ao negro”. (PIDEN, 2010) A título de exemplo, um jovem argentino criou uma página no Facebook chamada "Extermínio dos Negros de Merda". (NERI, 2008) No Brasil, os afrodescendentes são chamados de "macaco", "besta", "vagabundo", "filho da puta", "safado", "ladrão" e "nega fedorenta”. (VAN DIJK, 2005, p. 136137) Claramente, os insultos brasileiros estão associados à noção de negritude. Infelizmente, tais figuras são reproduzidas em livros didáticos infantis, nos quais pessoas negras são reiteradamente descritas como animais, socialmente subordinadas e representadas por outras formas estereotipadas. (SILVA JUNIOR, 2002, p. 34-38) Nos jornais colombianos, até mesmo o ar poluído de Cali é atribuído à suposta sujeira dos negros. (SALAZAR, 2008) Na Costa Rica, é comum que os negros sejam descritos como porcos, fedorentos, desalinhados e feios. (JIMÉNEZ CASTRO, 2001, p. 43) Em Cuba, "fazer coisas como um negro" é uma expressão comum para descrever uma atividade mal feita ou atos de delinquência. (RAVSBERG, 2003) A própria Academia de Ciências Cubana estabeleceu, em 2003, que dezenas de frases cubanas têm sido usadas para associar negros à delinquência e à inferioridade. (RAVSBERG, 2003) Isso é melhor exemplificado pelas frases populares como "Tinha que ser um negro" (AVELLANEDA, 2005) e "Não há negro bom, nem tamarindo doce”. (DUHARTE JIMÉNEZ; GARCÍA, 2005) No Equador, uma frase frequentemente repetida é a de que um negro correndo é um ladrão e um branco correndo é um atleta. (ANDALUZ PRADO, 2009) Isso ajuda a explicar os resultados de uma pesquisa feita em 2009, a qual demonstrou que cinco em cada sete equatorianos têm preconceito racial contra negros. (ANDALUZ PRADO, 2009) Até mesmo as autoridades do governo equatoriano se sentem à vontade para expressar suas ideias sobre o assunto. Um chefe de polícia declarou publicamente em 1995 que "existe um tipo racial que apresenta tendência a delinquir, a cometer atos horríveis... que é a raça negra, a qual está tomando conta dos centros urbanos do país, formando cinturões de pobreza que conduzirão à delinquência por causa da ignorância e insolência desses grupos”. (MUTEBA RAHIER, 1998, p. 421-430, 424) No México, os afro-mexicanos reagem aos estereótipos de "feios" e "escuros" focando em casamentos inter-raciais com pessoas de pele mais clara com a esperança de tornar a prole mais clara e, portanto, "melhorar a raça". (CASTELLANOS GUERRERO et al., 2009, p. 217, 233) Na Nicarágua, a expressão "100 negros por um cavalo” traduz diretamente a inferioridade do negro em relação 
ao valor de um único cavalo (STEPHENSON, 2011), dada a visão comum naquela sociedade de que negros são dependentes de drogas e bêbados. (SALINAS MALDONADO, 2009)² No Peru, são comuns as afirmações de que negros são criminosos, que só podem trabalhar em cargos subalternos, que são preguiçosos, que só conseguem raciocinar até o meio-dia, que são delinquentes e que as mulheres negras são prostitutas. Uma matéria feita por jornais peruanos em 2008 revelou um total de 159 adjetivos racistas diferentes para descrever pessoas de ascendência africana. (INFORME, 2008) Na Venezuela, a despeito do orgulho nacional de ser uma raça miscigenada ("café com leche”), a abundância de ditados racistas comumente repetidos inclui a frase "Mate um negro e tenha um dia Pepsi” ("lindo dia”). (GARCÍA, 2010) O vasto repertório de estereótipos raciais sobre afro-venezuelanos inclui: "Negros são perigosos, ladrões, cheiram mal, têm maus hábitos, desonram a imagem de uma empresa [...] não é culpa deles se eles são desse modo [...] negros, quando não fazem na entrada, fazem na saída”. (BOLÍVAR et al., 2009, p. 291-293)

Esses estereótipos raciais também são difundidos pela música popular venezuelana em letras como:

Mulher negra! [...] se você fosse branca e tivesse cabelo liso / minha mãe me disse agoniada para não casar com uma mulher negra porque quando ela dorme parece uma serpente enrolada / uma mulher negra com nariz grande não cozinha para mim porque ela guarda os bocados no buraco do nariz. (BOLÍVAR et al., 2009, p. 293)

Na América Latina, o discurso racial também é usado para demonstrar carinho, o que, inconscientemente, invoca o paternalismo do passado escravista. Por exemplo, a afeição é manifestada por expressões como "este é meu negro" ou "negrinho". Mesmo elogios direcionados a pessoas negras são reservados àquelas que "superaram” a negritude por apresentarem características "superiores”. Tais elogios racializados incluem "ele é negro, mas tem a alma/coração de um branco", “ela é negra, mas é bonita”, “ele é negro, mas é cheiroso e bem cuidado”. Embora essas afirmações não pretendam ser racistas, elas ativam estereótipos raciais sobre a inferioridade racial de negros. De fato, essa visão sobre as pessoas de ascendência africana estão tão arraigadas no tecido social

2 Em que se descreve o racismo na Nicarágua da perspectiva de uma mulher negra do Caribe. 
latino-americano que a presença de afrodescendentes em posições subalternas é tida como algo natural e lógico. Além do mais, a duradoura noção de que "racismo não existe" na América Latina faz com que aqueles que não são afetados pelo discurso de ódio não se disponham a reconhecer os danos causados aos grupos marginalizados.

Ademais, quando exemplos flagrantes de conduta racista recebem atenção da mídia latino-americana, eles são interpretados como atos de indivíduos isolados que não representam a tolerância racial que supostamente faz parte da cultura latino-americana. Essa dicotomia é bem exemplificada por um estudo que mostra que enquanto $87 \%$ dos entrevistados brasileiros não negros manifestaram preconceito racial nas respostas às perguntas da pesquisa, apenas $10 \%$ admitem ter algum tipo de preconceito racial. (DATAFOLHA, 1995) Do mesmo modo, enquanto $89 \%$ de todos os brasileiros afirmam existir racismo no Brasil, somente $4 \%$ admitem ter algum tipo de preconceito racial. (SANTOS; SILVA, 2005, p. 141-145) Dessa maneira, apesar da reputação de o Brasil ser uma terra de relações raciais "cordiais”, os brasileiros, como os demais latino-americanos, possuem bastante consciência das distinções de cor e de sua relevância hierárquica. Um etnógrafo que viajou para o Brasil para estudar a teoria da libertação, mas, ao invés disso, encontrou racismo, relata:

Observei que o problema da cor era uma presença constante na maneira como homens e mulheres se olhavam, escolhiam seus amores e cônjuges, moldavam seus corpos. Estava lá nas rodas de piadas, brincadeiras, insultos e acusações cotidianas. Estava lá no modo pelo qual as pessoas falavam umas com as outras e sobre as outras, em como elas se tocavam, ou não. (BURDICK, 1998, p. viii)

Na verdade, os brasileiros, como a maioria dos latino-americanos, não conseguem imaginar uma versão afro-brasileira de Barack Obama se autodeclarando afrodescendente. (VERISSIMO, 2008) Em resumo, apesar das diferenças regionais na demografia racial e do predomínio da expressão do discurso da miscigenação, em toda América Latina existe uma realidade antinegra comum.

Contudo, a negação latino-americana do racismo está profundamente arraigada nos ambientes racialmente hierarquizados. Esse dualismo foi viabilizado ao longo da história pelo desenvolvimento de comparações estratégicas com o sistema racial estadunidense, com a pretensão de descrever a América Latina como inocente por não ter recorrido ao racismo. Chamo isso de discurso da 
“inocência racial”. Nesse sentido, o Ariel Dulitzky, acadêmico latino-americano na área dos direitos humanos afirma que

Há certa presunção de superioridade moral em relação aos Estados Unidos muito difundida em nossa região. Raramente, uma conversa sobre racismo entre latino-americanos ocorre sem que se mencione a marcada incidência de racismo e discriminação racial que existe na terra dos nossos vizinhos do norte. (DULITZKY, 2005, p. 39, 42-50)

Por exemplo, na pesquisa BBC de 2005 sobre atitudes racistas latino-americanas, a seguinte invocação de inocência racial foi bastante observada:

Não acho que exista muito racismo na América Latina porque somos uma mistura de raças de todos os tipos, europeus, africanos, asiáticos e outras raças que existiram e existirão; mas entendo que exista muito racismo em outras partes, principalmente nos Estados Unidos e na Europa, lá é onde existe mais racismo. (IBEROAMÉRICA, 2005)

Em sua pesquisa sobre racismo no Peru contemporâneo, Suzanne Oboler (2005, p. 75-100) identificou que, assim como na maioria dos países do continente americano, as leis estadunidenses de segregação constituem a definição ideológica do racismo.

A América Latina tradicionalmente se orgulha de um passado sem leis de segregação racial ao estilo da legislação Jim Crow que vigorou nos Estados Unidos. Quando os latino-americanos avaliam as condições raciais de hoje, comparam-nas continuamente com a história de segregação racial estadunidense moldada pelas leis Jim Crow, e fazem afirmações como: "Não existe um racismo violento como em outras partes do mundo, como o neonazismo ou a segregação no sul dos Estados Unidos.” (IBEROAMÉRICA, 2005) “Este é um problema dos americanos." (OBOLER, 2005, p. 85) Por conveniência, o uso dos Estados Unidos como ponto de referência ofuscou a visão da situação de subordinação racial de pessoas de descendência africana na América Latina.

Ademais, a histórica ausência de leis de segregação racial do tipo Jim Crow é usada como justificativa para fazer oposição às demandas contemporâneas dos movimentos negros por políticas sociais racialmente conscientes. (DZIDZIENYO, 2005, p. 279-291) Por exemplo, ao discutir a possibilidade do uso de ações afirmativas no mercado de trabalho colombiano, um observador adverte 
"Isso seria como comprar uma passagem para um conflito que não conhecemos." (GALLO ROJAS, 2009, p. 7) No mesmo sentido, outro colombiano afirma: "Se não queremos criar um conflito racial que não existe neste país, teremos que baixar o tom das reivindicações raciais e propor soluções universais, como a luta contra a pobreza." (RODRÍGUEZ GARAVITO, 2009) ${ }^{3}$ Na mesma esteira, a reação brasileira ao uso de ações afirmativas em algumas universidades é denunciá-las como "a substituição da noção brasileira de democracia racial por uma discriminação positiva, ao estilo estadunidense, que generalizaria a polarização.” (VEGA SFRANI, 2006) A título de ilustração, um manifesto de grande circulação se opondo ao uso de ações afirmativas no Brasil se intitula "Não somos racistas: uma reação aos que querem nos transformar numa Nação Bicolor.” (KAMEL, 2006) Faz pouca diferença para esses críticos que as ações afirmativas, na realidade, tenham se originado na Índia, não nos Estados Unidos.

Todavia, frequentemente ignorado pelas comparações feitas com o passado estadunidense marcado pela legislação Jim Crow, e que favorecem o Estado, é o papel do Estado latino-americano na regulação das relações raciais. Especificamente, com a abolição da escravidão, as nações latino-americanas promulgaram leis de imigração restritivas e promoveram, com recursos estatais, uma política de imigração voltada explicitamente para o branqueamento da população e a proibição da imigração de pessoas de ascendência africana. Através das leis de imigração, afrodescendentes foram recolocados no lugar que ocupavam no período anterior à abolição, o de pessoas marginalizadas. Ademais, o direito costumeiro (por exemplo, a aplicação de regras não escritas aceitas pelo longo período de uso em vez de leis promulgadas e sancionadas) foi também usado como uma ferramenta de exclusão racial na América Latina.

\section{Direito costumeiro de regulação racial}

Não temos racismo porque aqui o negro conhece seu lugar. ${ }^{4}$

O direito costumeiro é particularmente relevante para examinarmos os projetos raciais do Estado porque frequentemente é necessária alguma coordenação

3 Em que cita Daniel Mera, diretor da Fundación Color.

4 Um ditado brasileiro sobre relações raciais. (MARTINS, 2008, p. 37-46) 
social para que convenções sociais sejam ratificadas. Isso pode ser surpreendente para os acadêmicos do direito de hoje, os quais raramente se aprofundam nas sutilezas do direito costumeiro, uma vez que cederam essa área de pesquisa aos antropólogos. (CHANOCK, 1991, p. 52-70, 53) Esse fato pode ser ainda mais surpreendente na área de estudos latino-americanos, na qual a história do direito costumeiro frequentemente é colocada em segundo plano, sem falar na aversão que existe em relação ao direito costumeiro no sistema jurídico atual, dominado por códigos civis. (ANZOÁTEGUI, 2001, p. 13)

Todavia, em linha com a tradição jurídica de direito romano adotada pelos países da América Latina, o direito costumeiro é uma fonte de direito desde as origens dos sistemas de direito civil e, nesse sentido argumento que não deve ser negligenciado como mecanismo de controle racial. (JOLOWICZ, 1967; PINTO, 1982, p. 126; WATKIN, 1999) Especificamente, o conceito de direito romano de ius non scriptum (direito não escrito) descreve as regras que surgem das práticas costumeiras não escritas e que se tornaram obrigatórias com o decurso do tempo, em contraposição ao ius scriptum (direito escrito), ou seja, regras escritas que foram deliberadamente elaboradas pelo legislador. Os usos do direito consuetudinário no direito civil, empregados aqui, ecoam as origens romanas como na conduta tácita de uma comunidade consagrada pelo uso prolongado. (WATSON, 1984, p. 561-576) Por exemplo, vários acadêmicos do direito observaram que o costume foi uma fonte de direito útil para o desenvolvimento da história do direito colonial espanhol no que diz respeito ao comércio e à mineração (MIROW, 2004), além de ter sido relevante para o desenvolvimento do direito latino-americano, inclusive o direito brasileiro. (ANZOÁTEGUI, 2001; CASTELLUCCI, 2008, p. 1-32; PINTO, 1982, p. 45; SAVASTANO, 2009, p. 651-667) As tradições de direito civil latino-americanas, fundadas no conceito romano de ius non scriptum, até os dias atuais reconhecem o costume como uma fonte do direito, ao lado das leis e regulamentos administrativos. (MERRYMAN; PÉREZ-PERDOMO, 2007) Apesar de o costume não ser necessariamente uma fonte do direito predominante no direito latino-americano, vale notar que o direito costumeiro é reconhecido como uma fonte do direito.

A visão desta obra sobre a aplicabilidade histórica do direito costumeiro à população em geral contrasta com a visão contemporânea desse sistema jurídico, como uma prática mais restrita de aplicação de normas jurídicas a um grupo específico ou a um subgrupo da população, como no caso das populações 
indígenas ou tribos africanas. (GOODRICH, 1986, p. 64) Essa dupla conotação do direito costumeiro também era adotada no contexto do direito romano, segundo o qual o direito costumeiro era aplicado às relações entre os cidadãos romanos em geral e também eram consideradas aplicáveis normas costumeiras oriundas dos demais subgrupos populacionais dentro do próprio Império Romano. (VINOGRADOFF, 1925, p. 23)

A concepção moderna de direito costumeiro como sistema específico de subgrupos populacionais indígenas, tal como discutido por autores como Rachel Sieder e muitos antropólogos que a ele atribuem o nome de "direito tradicional", não é a concepção adotada neste livro. (FITZPATRICK, 1984, p. 20-27; SIEDER, 2002) Isso porque o foco atual em direito costumeiro indígena enfatiza como sistemas jurídicos paralelos, o da população majoritária hegemônica e o da população indígena minoritária, podem apresentar perigo de um conflito de normas entre o Estado e as práticas costumeiras de um subgrupo indígena da população, como no caso dramático em que o direito costumeiro na África colonial serviu aos administradores da elite branca. (CHANOCK, 1989, p. 72-88) Pelo contrário, este livro busca elucidar como o uso implícito do direito costumeiro geral pelo próprio Estado, para que este faça valer uma ordem social particular, em vez de se debruçar sobre os desafios apresentados ao Estado por práticas costumeiras de grupos específicos. Neste livro, a noção de direito costumeiro geral empregada remonta à noção de Bentham de direito costumeiro como algo que "esconde os interesses sinistros da elite dominante". (PERREAU-SAUSSINE; MURPHY, 2007, p. 5) Em resumo, o direito costumeiro pode representar a imposição de normas obrigatórias por algumas pessoas em relação a outras. (CHANOCK, 1985)

O direito costumeiro não precisa ser codificado posteriormente para que se torne obrigatório. (SHELEFF, 1999, p. 378, 385) Em verdade, as fontes romanas, como os institutos de Justiniano, consideravam o costume como direito quando as comunidades o aceitavam como tal conforme evidenciado pela aplicação das normas formais e informais de direito costumeiro. (BEDERMAN, 2010, p. 17) Na realidade, quando o direito costumeiro está totalmente integrado a uma sociedade, constituindo uma prática estatal, existe pouco incentivo para que os costumes sejam codificados. O que mais importa é se existe um sentimento de obrigação jurídica regendo uma determinada conduta, vinculando-a ao costume e exigindo conformidade com o mesmo. Disso decorre que a aceitação de uma norma social na condição de norma jurídica passa a ser comprovada pelo uso dos recursos estatais para fazer 
valer tais regras no âmbito geral. (PETERSEN, 1995, p. 174) No contexto latino-americano, o uso dos recursos estatais (por exemplo, o poder de polícia aplicando segregação racial e a alocação de incentivos financeiros para promover a imigração de europeus) é o fator-chave para transformar convenções sociais em direito costumeiro. Isso porque o direito costumeiro se refere a um subgrupo de normas sociais "escolhidas para serem aplicadas de forma especial”. (MURPHY, 2007, p. 76)

Avaliar o tratamento conferido aos afrodescendentes através das lentes do direito costumeiro ajuda a elucidar a dimensão "jurídica" da história racial latino-americanas. Por exemplo, os depoimentos de afro-brasileiros feitos no sul do Brasil, no período pós-abolição, amplamente evidenciam os costumes arraigados de segregação racial - nas ruas, praças, parques e jardins públicos, tanto nas capitais como no interior -, mantidos pela polícia, a qual costumava prender os afro-brasileiros. Tais práticas podem ser caracterizadas como direito costumeiro na medida em que elas eram impostas por meio de sanções físicas e agentes estatais se sentiam obrigados a aplicar as normas vigentes na comunidade, a despeito da inexistência de um dispositivo legal expresso ou uma declaração legal explícita de que os costumes eram direito. Chamo isso de "direito costumeiro de regulação racial" para demonstrar as maneiras pelas quais a norma social de exclusão racial efetivamente operou como um sistema jurídico, no qual os recursos estatais e de coerção foram utilizados para garantir a marginalização de pessoas de ascendência africana. Dessa maneira, o uso que faço do direito costumeiro enfoca as maneiras pelas quais as regras de exclusão racial foram mais do que convenções sociais, eram equivalentes ao direito. Levar em conta a importância do papel do direito costumeiro aumenta nossa compreensão sobre a regulação racial na América Latina.

As discussões acadêmicas sobre direito costumeiro na América Latina frequentemente observam que muitos países na região não conferem status de direito costumeiro às práticas consideradas contra legem (contrárias ao direito), ou seja, contrárias ao direito legislado. (GUZMÁN BRITO, 1987) Ao mesmo tempo, acadêmicos também observam que vários exemplos de direito costumeiro reconhecido, não obstante, transgridem o direito legislado. (PINTO, 1982, p. 126-128; SANTAMARÍA, 2009, p. 249-264) No caso específico do direito costumeiro de regulação racial, o único argumento para que o mesmo seja contra legem, portanto sem status jurídico, seria a existência de normas igualitárias que proliferaram nas constituições da região após as respectivas 
independências. Esse argumento, entretanto, pode ser facilmente descartado se considerado que as provisões igualitárias eram dirigidas aos títulos de nobreza e à abolição de privilégios monárquicos remanescentes.

Por exemplo, uma disposição igualitária típica no período pós-colonial pode ser encontrada na Constituição Argentina de 1853, que declarava:

A nação argentina não admite prerrogativas de sangue ou de nascimento; privilégios pessoais e títulos de nobreza não existem. Todos os habitantes são iguais perante a lei, e admissíveis a qualquer emprego público desde que atendam às exigências do cargo. (ARGENTINA, 1853, art. 16)

A aplicação restritiva, no século XIX, da igualdade constitucional às questões de nobreza, também é percebida nas disposições que excluíam analfabetos e pobres do direito de votar, uma vez que seriam pessoas de classe inferior que, portanto, não deveriam ter garantidos os plenos direitos de cidadania. Na medida em que a igualdade constitucional da América Latina do século XIX se limitou a homens brancos, o direito costumeiro de regulação racial não pôde ser considerado uma derrogação contra legem da norma constitucional. Ademais, a América Latina do século XIX considerava as constituições documentos políticos sem efeitos jurídicos diretos e imediatos, salvo se houvesse lei regulando suas normas e, assim, nunca questionou se os costumes de regulação racial seriam considerados contra legem e, portanto, não obrigatórios juridicamente.

Debates sobre direito costumeiro normalmente se ocupam de como costumes, enquanto direito não escrito, que podem ser aplicados diretamente em juízo, ou como normas de um subgrupo, que podem coexistir na condição de direito costumeiro em um sistema soberano mais amplo de leis formais sancionadas por um soberano. Este livro examina somente o uso implícito do direito costumeiro fora do judiciário, por atores estatais, visando ao fortalecimento do aparato que sustenta a hierarquia racial existente. Os capítulos 2 e 3 analisam as práticas costumeiras que o Estado empregou no período após a abolição para manter a segregação racial, excluindo as pessoas de ascendência africana de lugares públicos, impondo normas racistas nas escolas públicas, estabelecendo normas racistas contra religiões de matriz africana e estruturando recenseamentos que marginalizavam as pessoas de ascendência africana, primeiro na América Hispânica e depois no Brasil. 
O exame do amplo repertório de práticas costumeiras racialmente excludentes, juntamente com a legislação e os subsídios oferecidos às políticas de restrição à imigração, faz cair por terra a noção de que os Estados latino-americanos não tiveram regulação racial e, portanto, eram inocentes. Sem dúvida, as particularidades do contexto legal latino-americano não podem ser diretamente comparadas com a história de segregação racial nos Estados Unidos por meio das leis Jim Crow. Apesar disso, vale ressaltar como a ação estatal na América Latina voltada para a subordinação racial teve um efeito similar na marginalização de pessoas de ascendência africana na região. De fato, o verdadeiro mal das restrições raciais da legislação Jim Crow estadunidense não residia tanto no fato de que as leis de segregação foram escritas e codificadas, mas no fato de evidenciarem a ação estatal de discriminação racial revelada por essas leis. Similarmente, o direito costumeiro latino-americano traz à tona o papel pernicioso do Estado na regulação racial.

Enquanto é verdade que as assimetrias históricas e sociopolíticas na região são enormes, o objetivo aqui é explicitar aspectos comuns, frequentemente desprezados, de como a ordem jurídica latino-americana funda-se enormemente no privilégio racial e continua produzindo significativas disparidades raciais em várias áreas políticas e socioeconômicas, como detalhado no capítulo 4. Por essa razão, o livro enfoca o estabelecimento do direito costumeiro racialmente excludente no século XIX, para em seguida abordar as preocupações contemporâneas com a estratificação racial. Menos atenção é dada aos anos seguintes, nos quais a desigualdade racial permaneceu intacta, para dar mais atenção ao modo como o legado do direito costumeiro de regulação racial afeta os afrodescendentes hoje.

Desse modo, este livro busca romper a narrativa tradicional de que a América Latina tem um passado jurídico racialmente benigno e reexamina sua importância para o atual desenvolvimento de leis de igualdade racial na região. Dada a resistência das elites às políticas públicas de igualdade racial patrocinadas pelo Estado, é essencial fornecer um quadro completo do envolvimento estatal na manutenção da hierarquia racial. Por seu turno, o panorama elaborado neste livro oferece suporte adicional para as políticas de igualdade racial latino-americanas que estão sendo contestadas no judiciário e no debate público. Ao detalhar a cumplicidade histórica dos estados latino-americanos em criar e manter hierarquias raciais, o livro joga por terra o mito da inocência racial da América Latina e também apoia a reivindicação dos movimentos por justiça social decorrente de um engajamento estatal direto na promoção da igualdade racial. Deve 
ficar claro que o estudo das ações estatais feito nesta obra não se limita ao esforço de procurar justificar a participação estatal na promoção de políticas de igualdade racial por causa do envolvimento histórico do Estado na produção de desigualdade racial. A desigualdade racial é uma preocupação premente que deve ser levada em consideração pelos agentes estatais a despeito do grau de participação do Estado na história da produção de desigualdade racial. A partir dessa perspectiva, o livro aborda de maneira mais ampla o poder do discurso da ação estatal para os indivíduos que participam de movimentos sociais, em uma tentativa de acabar com a ideia de inocência racial por parte do Estado que, por seu turno, impede que a sociedade efetivamente busque igualdade racial. Nesse sentido, o presente livro serve não somente como uma narrativa de como o direito foi utilizado na construção da hierarquia racial latino-americana, mas também como uma avaliação da importância das iniciativas estatais contemporâneas com o objetivo de erradicar o racismo na região.

O capítulo 5 examina as várias iniciativas legais que têm sido adotadas na América Latina para superar o racismo. Constituições multiculturais, leis de titulação coletiva de terras, leis contra a discriminação no mercado de trabalho, leis sobre acesso a lugares públicos, leis sobre discursos de ódio e o direito internacional dos direitos humanos serão analisados nesse capítulo. Atenção especial será dirigida à esperança desproporcional que é depositada no direito criminal enquanto resposta jurídica à longa história de marginalização e negação do racismo. As dificuldades em potencial de lidar de forma plena com a discriminação racial dentro do contexto criminal serão discutidas juntamente como enfoque exclusivamente interpessoal, próprio desse tipo de abordagem, em detrimento de uma abordagem institucional muito mais ampla que trate da discriminação racial sistêmica.

O capítulo 6 examina a liderança brasileira no uso de ações afirmativas na América Latina, esmiuçando a trajetória das políticas de ações afirmativas baseadas em raça, a partir de 2001 no Brasil. Em seguida, investiga a crescente oposição feita a esse tipo de política devido ao aumento de ações afirmativas baseadas em raça em instituições de ensino superior de elite, bem como as demandas judiciais apresentadas contra essas políticas. O capítulo enfatiza os sucessos dos programas, portanto serve como referência para os demais países da América Latina, mas também examina como a visão míope da região sobre o papel do Estado na criação da subordinação racial pode atrapalhar o estabelecimento de políticas de ação afirmativa mais amplas. 
A conclusão do livro, o capítulo 7, traz insights de como a análise da realidade latino-americana pode ser útil para os movimentos de justiça racial estadunidenses. A luta afro-latino-americana para desvelar o discurso de um Estado racialmente inocente, o qual camufla desigualdades raciais persistentes, pode ajudar a esclarecer a complexa realidade racial nos Estados Unidos nos dias de hoje. A bem-sucedida batalha dos movimentos por direitos civis contra as leis Jim Crow agora coloca as minorias raciais nos Estados Unidos em situação análoga à situação vivida pelos afrodescendentes na América Latina: ter que lutar contra uma hierarquia racial não baseada em uma discriminação jurídica formal. 